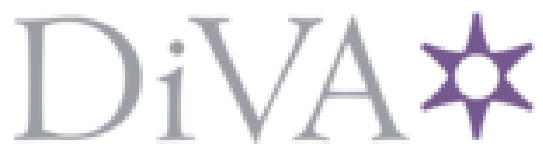

http://www.diva-portal.org

This is the published version of a paper published in Economics Letters.

Citation for the original published paper (version of record):

Angelova, V., Giebe, T., Ivanova-Stenzel, R. (2018)

Does a short-term increase in incentives boost performance?

Economics Letters, 166: 31-34

https://doi.org/10.1016/j.econlet.2018.02.004

Access to the published version may require subscription.

N.B. When citing this work, cite the original published paper.

Permanent link to this version:

http://urn.kb.se/resolve?urn=urn:nbn:se:lnu:diva-71049 


\title{
Does a short-term increase in incentives boost performance?
}

\author{
Vera Angelova $^{\mathrm{a}}$, Thomas Giebe ${ }^{\mathrm{b}, *}$, Radosveta Ivanova-Stenzel ${ }^{\mathrm{a}}$ \\ a Technische Universität Berlin, Department of Economics and Management, Strasse des 17. Juni 135, D-10623 Berlin, Germany \\ b Linnaeus University, Department of Economics and Statistics, S-351 95 Växjö, Sweden
}

\section{H I G H L I G H T S}

- Study a dynamic competitive environment in a real-effort experiment.

- A one-time increase in incentives in a sequence of equally incentivized contests.

- Increased effort only in the contest with high incentives.

- A tendency to slack after times of high incentives.

- No boost in total performance.

\section{GRAPHICAL ABSTRACT}

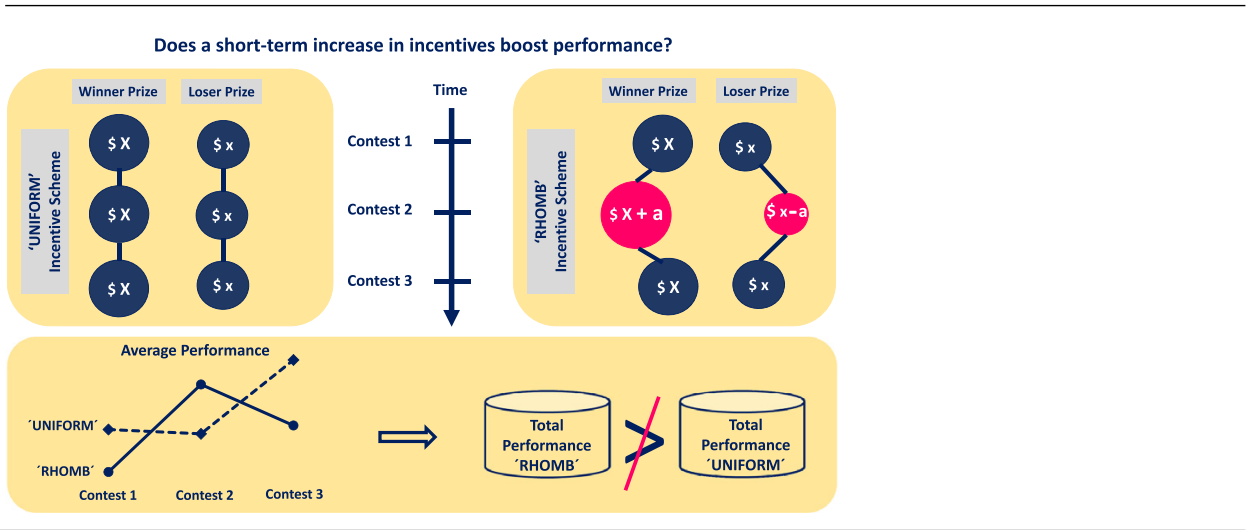

\section{A R T I C L E I N F O}

\section{Article history:}

Received 27 December 2017

Received in revised form 2 February 2018

Accepted 2 February 2018

Available online 17 February 2018

\section{JEL classification:}

C91

D91

$\mathrm{J} 22$

J33

L2

M5

Keywords:

Contest

Tournament

Real-effort

Experiment

Contract theory

Forward-looking

\section{A B S T R A C T}

If agents are exposed to continual competitive pressure, how does a short-term variation of the severity of the competition affect agents' performance? In a real-effort laboratory experiment, we study a one-time increase in incentives in a sequence of equally incentivized contests. Our results suggest that a short-term increase in incentives induces a behavioral response but does not boost total performance.

(C) 2018 The Author(s). Published by Elsevier B.V. This is an open access article under the CC BY-NC-ND license (http://creativecommons.org/licenses/by-nc-nd/4.0/).

\section{Introduction}

* Corresponding author.

E-mail addresses: vera.angelova@tu-berlin.de (V. Angelova), thomas.giebe@lnu.se (T. Giebe), ivanova-stenzel@tu-berlin.de (R. Ivanova-Stenzel).
It is generally accepted in economic theory that competitive pressure improves agents' performance (see, e.g., Jenkins Jr. et al., 
1998; Dechenaux et al., 2015 for empirical support). ${ }^{1}$ Thus, one way to improve performance in a dynamic competitive environment may be to vary the severity of competition over time. For example, it is a common recommendation for sales managers to use short-term contests in order to boost performance (Roberge, 2015).

However, whether and how a short-term increase in incentives will affect total performance is not obvious due to several countervailing effects. First, performance under continual competitive pressure may cause stress and fatigue. ${ }^{2}$ If fatigue or stress play a role, higher effort in one period increases effort cost in the next period, leading to a decline in effort after times of high incentives. Second, the change in incentives over time may influence agents' attitudes. They may perceive periods with low incentives as less valuable due to the presence of periods with higher incentives. Therefore, effort in periods with low incentives may decrease in anticipation of periods with high incentives or after experiencing high incentives. In summary, it is not clear whether total effort will be higher under variable incentives than under uniform incentives.

The literature so far does not provide an answer to this question. There are a few empirical papers that study how incentives in competitive environments affect behavior over time. However, they focus either on forward-looking behavior (e.g., Lackner et al., 2015; Raya, 2015) or on ex-post effort choice after periods of high incentives (e.g., McGee and McGee, 2013; Johnson and Salmon, 2016).

We study experimentally the effect of a short-term increase in incentives in a dynamic competitive environment, i.e., in a sequence of three two-player contests. We compare an incentive scheme where all contests feature "low" and uniform incentives over time with an incentive scheme where the pattern of uniform incentives is interrupted by a period of "high" incentives. The setting we investigate has two important features. First, the total amount of incentive pay, i.e., the sum of winner and loser prize in all contests and for all incentive schemes, is always the same. Second, in contrast to previous studies, we do not provide subjects with feedback about own earnings between contests. In this way, we focus on incentive effects only and control for feedback effects such as discouragement (see, e.g., Johnson and Salmon, 2016). Our results suggest that a one-time increase in incentives improves performance in the short run but does not lead to an increase in total performance. The latter finding is mainly driven by slacking after times of high incentives. This study adds to the growing literature on behavior in dynamic competitive environments, but also provides useful insights for practitioners who design compensation plans.

\section{Experimental design}

The computerized real-effort laboratory experiment was divided into two identical parts consisting of the same sequence of three contests. Subjects received instructions for part two only after part one was completed. Part one was conducted to allow subjects to get acquainted with the task and the strategic environment. We paid for all contests and all parts and used a between-subjects design. $^{3}$

In each contest, subjects worked for eight minutes on the real effort slider task developed by Gill and Prowse (2012). Subjects were supposed to move sliders from position 0 to position 50

\footnotetext{
1 This assumes that agents do not exit the game by shirking or choking.

2 The potential negative (and costly) consequences can be inefficient work outcomes (due to bad judgments and inferior decisions) and even sick-leave, burnout or an early exit from the work force (Kant et al., 2003).

3 All prizes are stated in ECU (Experimental Currency Unit) with $100 \mathrm{ECU}=0.5$ EUR. For the instructions see the supplementary material.
}

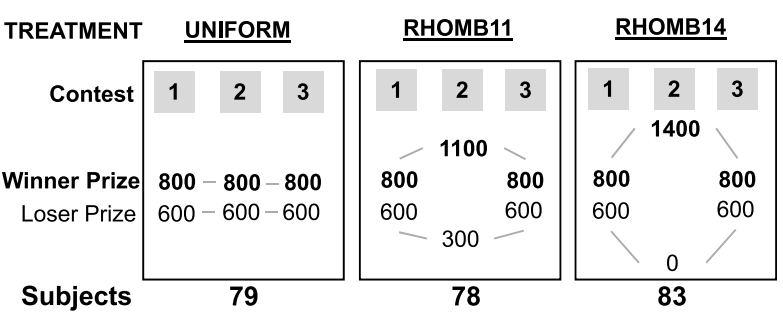

Fig. 1. Treatments and number of subjects.

(the middle of 100 possible integer positions) using the computer mouse only. In each contest, a new screen with 48 sliders would appear every two minutes to ensure that running out of work was impossible, and there was a 20 seconds break between contests. ${ }^{4}$ At the end of each contest, subjects were randomly paired. The subject with the higher number of correctly positioned sliders received the winner prize and the other subject the loser prize. ${ }^{5}$ If tied, subjects equally shared the sum of the winner and the loser prize. An on-screen count informed subjects about their own performance (i.e., the number of correctly positioned sliders) at any time. However, they were neither informed about the performance of others, nor whether they won or lost any of the contests.

Fig. 1 gives an overview of the treatments and specifies winner and loser prizes as well as the number of subjects per treatment. 'RHOMB' and 'UNIFORM' refer to the shape of the prize structure within a treatment, and the number in RHOMB to the winner prize in the second contest. In the UNIFORM treatment, the three contests were identically incentivized, i.e., the prize spreads were the same in all contests. ${ }^{6}$ Within and between the RHOMB-treatments, we varied the winner and the loser prize across contests to get different prize spreads, and thus different incentives while the total amount of incentive pay remained constant at 1400 ECU across contests and treatments. Subjects were informed about winner and loser prizes in all three contests before they launched each part of the experiment.

The experiment was conducted at Technische Universität Berlin and most participants were students with a major in economics, natural sciences, or engineering. The gender composition across treatments was very similar, with a share of males between $55 \%$ and $61 \%$. Note that, due to the absence of feedback between contests, each subject yields an independent observation.

\section{Results}

In our analysis, we measure performance as the number of correctly positioned sliders. For ease of comparison across treatments we also use a normalized measure of performance. The latter is the absolute difference between a subject's performance in each contest and that subject's performance in the last contest of part one. $^{7}$

Fig. 2 plots the average normalized performance across contests and treatments. In part one, we observe a steady significant growth in performance within treatments and no significant differences in performance across treatments. ${ }^{8}$ Subjects seem to predominantly

\footnotetext{
4 Real-life working conditions do not typically exhibit sufficient rest between working periods, see, e.g., Kant et al. (2003).

5 We also paid $1 \mathrm{ECU}(=0.005 \mathrm{EUR})$ per correctly positioned slider.

6 The prize spread is the difference between the winner and the loser prize.

7 This normalization accounts for individual differences in performance in part one, e.g., due to learning dynamics.

8 The pairwise comparisons across treatments for a given contest do not yield significant results. In contrast, the difference in performance between contest 1 (resp. 2) and 2 (resp. 3) within a treatment is significant for all treatments.
} 

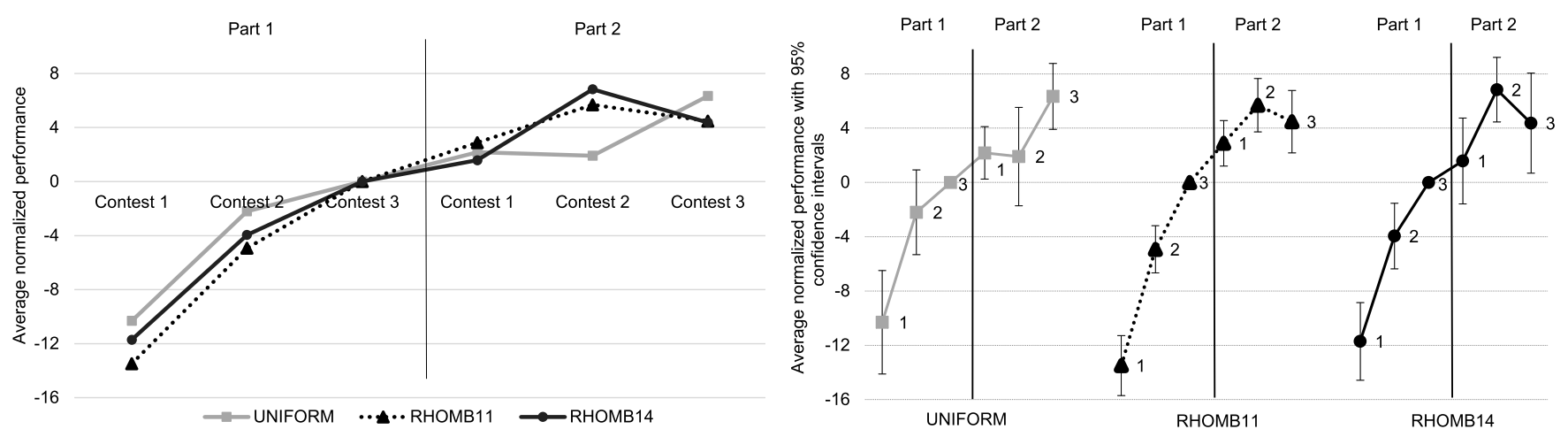

Fig. 2. Average normalized performance by contest and treatment.

Table 1

OLS regressions (part two).

\begin{tabular}{lll}
\hline & $\begin{array}{l}\text { Total } \\
\text { performance }\end{array}$ & $\begin{array}{l}\text { Total } \\
\text { normalized } \\
\text { performance }\end{array}$ \\
\hline RHOMB11 & 10.90 & 2.62 \\
RHOMB14 & $(10.44)$ & $(4.35)$ \\
Constant & -3.521 & 2.35 \\
& $(10.28)$ & $(4.28)$ \\
Observations & $280.8^{* * *}$ & $10.43^{* * *}$ \\
R-squared & $(7.358)$ & $(3.06)$ \\
& & 240 \\
\hline
\end{tabular}

Standard errors in parentheses.

${ }^{* * *} p<0.01,{ }^{* *} p<0.05,{ }^{*} p<0.1$.

learn in part one, and they do so at a similar pace in all treatments. Thus, they enter part two being similarly familiar with the task and presumably similarly exhausted. ${ }^{9}$ The subsequent analysis will therefore focus on part two.

We first test whether the introduction of higher competitive pressure indeed leads to higher performance. ${ }^{10}$ In part two, we observe a strong reaction to the increase in incentives. While performance is virtually the same in contests 1 and 2 in the UNIFORM treatment (see Fig. 2), it is significantly higher in contest 2 (high incentives) than in contest 1 (low incentives) in both RHOMBtreatments (both $p \leq 0.004$, paired $t$-test). ${ }^{11}$

Having established that subjects respond to a change in incentives, we can now move to our key question: Does a short-term increase in incentives boost total performance?

Result: The one-time increase in incentives within a sequence of contests does not improve total performance.

OLS regressions of total performance and total normalized performance on treatment dummies for RHOMB11 and RHOMB14, using UNIFORM as a reference category (see Table 1) do not reveal any significant difference between the UNIFORM incentive scheme and both RHOMB treatments (with variable incentives). We also compare the distribution of total performance across treatments (see Fig. 3) using a two-sample Kolmogorov-Smirnov test. We cannot reject the null hypothesis of equality of distributions neither when comparing UNIFORM with RHOMB14 ( $p=0.822)$, nor when comparing UNIFORM with RHOMB11 $(p=0.532)$. We also do not find any difference in average total performance between

\footnotetext{
9 A more detailed analysis of part one is provided in the supplementary material. 10 The number of subjects in part two who chose not to compete is negligible: two in UNIFORM and two in RHOMB14. Results do not change if we exclude those subjects from the analysis.

11 Throughout the paper we report two-sided tests.
}

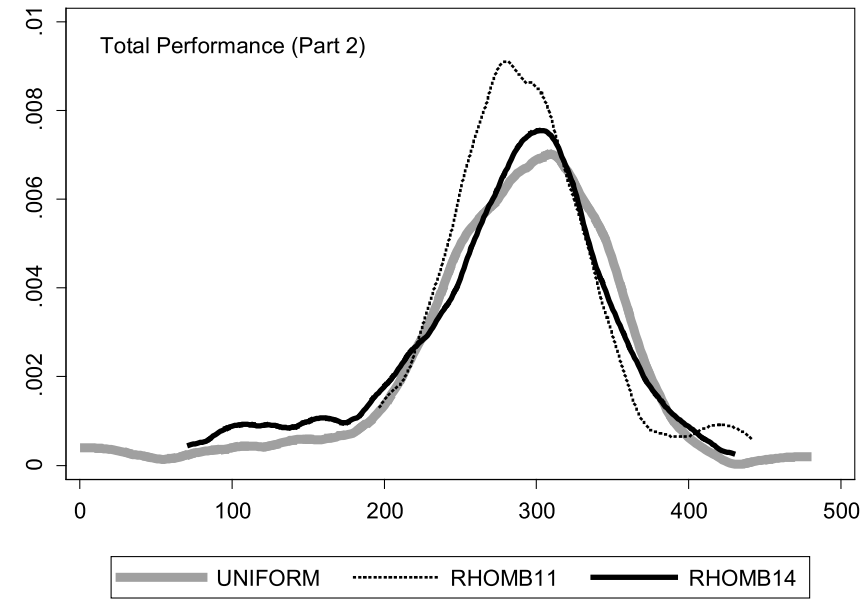

Fig. 3. Distribution of total performance in part two by treatment.

UNIFORM and both RHOMB-treatments when applying a MannWhitney-U test ( $p=0.9273$ for UNIFORM vs. RHOMB11, and $p=0.6462$ for UNIFORM vs. RHOMB14). All these tests suggest that total performance is not significantly different between the two incentive schemes.

What can account for the absence of a boost in total performance? A closer look at changes in performance between the contests in part two provides an explanation (see Fig. 2). The average change in performance from contests 2 to 3 in UNIFORM is positive in contrast to the RHOMB treatments where the average change is negative. Indeed, a difference-in-differences approach reveals significant effects between UNIFORM and RHOMB11 ( $p=0.007$, $t$-test), and between UNIFORM and RHOMB14 ( $p=0.013, t$-test). This suggests a tendency to slack after times of high incentives. There are two potential reasons for why this is the case. First, subjects in the RHOMB-treatments may be more tired than in UNIFORM and therefore not able to increase their performance in contest 3 as subjects in UNIFORM do. Second, subjects in the RHOMB treatments may not be willing to work hard when incentives drop because they may perceive working for the lower incentives in contest 3 as less attractive after experiencing a contest with higher powered incentives. We plan to disentangle the two effects in future research.

Another interesting question is whether subjects strategically anticipate a change in incentives. The average normalized performance in contest 1 (part two) is not significantly different between UNIFORM and both RHOMB treatments (both $p \geq 0.5834, t$-test). ${ }^{12}$ 
Therefore, we can neither confirm nor exclude forward-looking behavior.

\section{Conclusions}

In a real effort experiment, we study how a variation of the severity of competition over time affects agents' performance. We compare two incentive schemes where agents either participate in a sequence of identically incentivized contests (scenario UNIFORM) or the pattern of 'low' and uniform incentives is interrupted by a contest with 'high' incentives (scenario RHOMB). We find that introducing a contest with a large prize spread boosts performance in that contest, but does not result in an increase in total performance. $^{13}$

Most of this zero-net-effect result is explained by slacking after the contests with high incentives. Potential reasons for this drop in effort are stress, fatigue and/or a discounting in the perception of low incentives after times of high incentives. For example, if fatigue is a major determinant of these results, longer rest periods would weaken the tendency to slack after times of high incentives. If, however, the discounting of relatively small prizes is the main explanation, then resting as such might not substantially affect results. We can exclude discouragement effects as an explanation, as subjects did not receive feedback on winning and losing between contests. Furthermore, we do not find sufficient evidence for strategic resting or forward-looking behavior.

In summary, our results confirm the conventional belief that higher incentives lead to higher effort in the short run. But they also reveal the existence of countervailing behavioral effects (before and) after times of high incentives in dynamic competitive environments. Therefore, the simple static formula "high(er) incentives induce high(er) performance" cannot be applied unconditionally in dynamic real-life working environments. This should be considered by practitioners when designing incentive schemes.

\section{Acknowledgments}

We thank participants of ESA 2015, the Berlin Behavioral Economics Workshop (BBE), the responsible editor of Economics
Letters, and an anonymous referee for helpful comments. In particular, we thank David Danz, Paul Schweinzer, and Michel Tolksdorf. Financial support by Deutsche Forschungsgemeinschaft through CRC TRR 190 "Rationality and Competition" as well as support by the Berlin Centre for Consumer Policies (BCCP) are gratefully acknowledged.

\section{Appendix A. Supplementary data}

Supplementary material related to this article can be found online at https://doi.org/10.1016/j.econlet.2018.02.004.

\section{References}

Dechenaux, E., Kovenock, D., Sheremeta, R.M., 2015. A survey of experimental research on contests, all-pay auctions and tournaments. Exp. Econ. 18 (4), 609669. http://dx.doi.org/10.1007/s10683-014-9421-0.

Gill, D., Prowse, V., 2012. A structural analysis of disappointment aversion in a real effort competition. Amer. Econ. Rev. 102 (1), 469-503. http://dx.doi.org/ 10.1257/aer.102.1.469.

Goette, L., Huffman, D., 2006. Incentives and the allocation of effort over time: The joint role of affective and cognitive decision making, IZA DP No. 2400.

Jenkins Jr., G.D., Mitra, A., Gupta, N., Shaw, J.D., 1998. Are financial incentives related to performance? A meta-analytic review of empirical research. J. Appl. Psychol. 83 (5), 777-787. http://dx.doi.org/10.1037/0021-9010.83.5.777.

Johnson, D., Salmon, T.C., 2016. Sabotage versus discouragement: Which dominates post promotion tournament behavior? South. Econ. J. 82 (3), 673-696. http: //dx.doi.org/10.1002/soej.12115.

Kant, I., Bültmann, U., Schröer, K., Beurskens, A., Van Amelsvoort, L., Swaen, G., 2003. An epidemiological approach to study fatigue in the working population: the Maastricht Cohort Study. Occup. Env. Med. 60 (Suppl 1), i32-i39. http: //dx.doi.org/10.1136/oem.60.suppl_1.i32.

Lackner, M., Stracke, R., Sunde, U., Winter-Ebmer, R., 2015. Are competitors forward looking in strategic interactions? Evidence from the field, IZA DP No. 9564.

McGee, A., McGee, P., 2013. After the tournament: Outcomes and effort provision, IZA DP No. 7759.

Raya, J.M., 2015. The effect of strategic resting in professional cycling: evidence from the Tour de France and the Vuelta a España. Eur. Sport Man. Q. 15 (3), 323-342. http://dx.doi.org/10.1080/16184742.2015.1021825.

Roberge, M., 2015. The right way to use compensation. Harv. Bus. Rev. 93 (4), 70-75.

12 OLS regression results confirm the results of all reported $t$-tests.

13 Goette and Huffman (2006) also report a zero net effect on total performance in a dynamic environment although in a different setting. They measure performance of bicycle messengers who initially face a lower piece rate, which is then increased once and forever. Although messengers initially react to the piece rate increase, their performance drops in the course of the day, such that their total performance does not differ between the two piece rates. 